...the speakers on many courses or

conferences are selected for their ability to

speak or their popularity - not for their

proven expertise or scientific credibility.

\title{
Style over substance
}

Editing a scientific journal over the last 12 years has helped heighten my awareness of the importance of distinguishing between style and substance, something I was not so adept at before I was appointed to the $B D J$. Just because something is explained well, either in writing or verbally, does not mean it is correct or true (or even relevant). Yet we have a tendency to believe that papers or articles that read well or lectures or presentations that are delivered with expertise and charisma are important, relevant and true. This applies to virtually all forms of media, but is especially relevant in publications and in the educational environment.

of course the reverse does not automatically follow. A poorly written article or a badly prepared lecture is not necessarily any more correct than a well-written or well spoken one, but it may be. Our difficulty, as readers or listeners, is to identify what we can believe and what we cannot. To make matters worse, when we don't know the answer we tend to believe our prejudices, which are formed from past experiences. For example I suspect most of us have read something in a newspaper or magazine which we know to be incorrect, and thus assume that if the paper gets one story wrong it probably gets others wrong too. As a result our faith in its ability to provide an accurate story has gone, and it has gone forever.

But, although I have grouped the written and spoken word together, there are major differences in the way the content is checked prior to the audience receiving it. When a manuscript is submitted to a journal for peer review it goes through an intensely rigorous refereeing process, and unsubstantiated statements are quickly identified and usually omitted from the final result. Usually no such process occurs in postgraduate education, providing lecturers with much more freedom to make unsubstantiated statements that carry some authority which tend to be believed (by the audience) to be true. This is especially so when the lecturers are good at presentation and tell the audience what it wants to hear. I can remember an example that demonstrates this quite clearly from the BDA conference in Belfast a couple of years ago. Two speakers were on stage talking about the same topic. The first made a number of totally unsubstantiated statements, but because he spoke charismatically he was believed totally by many in the audience. The second speaker provided the audience with a well-researched talk providing evidence for all of the points made, but because the talk covered research topics it was not so well received. Many in the audience fell for style over substance.

We have a good system of peer review in scientific publishing, but nothing (as far as I know) in courses, conferences and seminars. In fact the speakers on many courses or conferences are selected for their ability to speak, their popularity or in many cases because the course organiser has heard them - not their proven expertise or scientific credibility. This is hardly surprising given the commercial profits to be made, but is it the best way? Perhaps more importantly, is it the ethical way?

I believe more should be done to peer review (or accredit) speakers who have the authority and credibility of the established postgraduate system, in the same way that we have editors for scientific journals. This is not an easy task, with immense cost implications. But if we don't do it we must answer in the future to both society and our patients who may suffer the effects of treatment provided on the basis of anecdote only.

Mike Grace Editor m.grace@bda.org doi: $10.1038 /$ sj.bdj.4811914 